\title{
Educar en el perdón
}

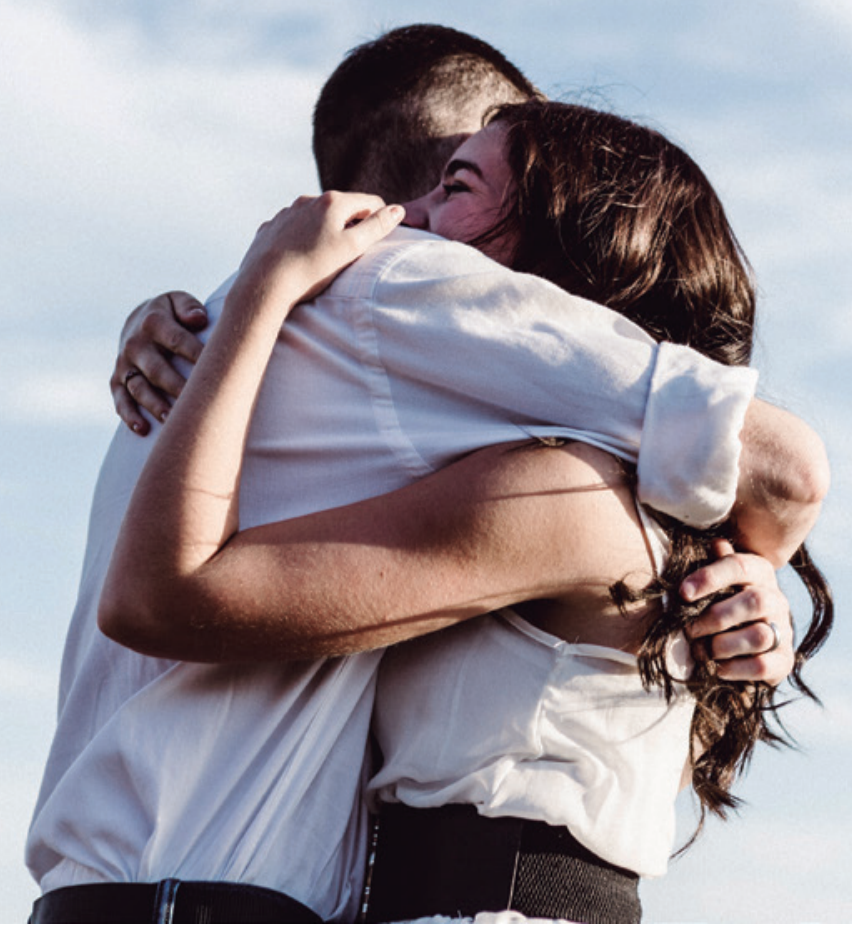

En este artículo se revisan los dos ámbitos fundamentales de aprendizaje del perdón: la familia y la escuela. Se profundiza en la comprensión del concepto de perdón, sus facilitadores y el papel de la religiosidad/ espiritualidad en él. Se subrayan los beneficios del perdón. Finalmente se proponen programas que ayudan en la consecución del perdón.

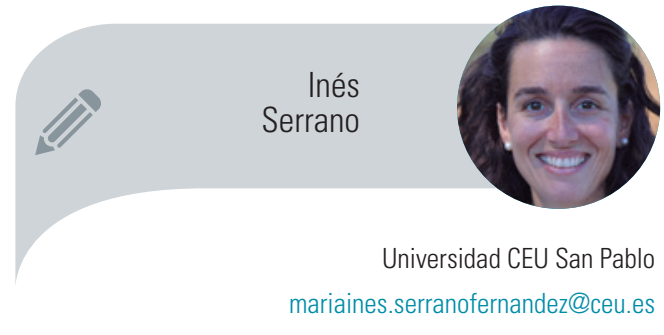

María Prieto Universidad Pontificia Comillas mprieto@comillas.edu

Javier López Universidad CEU San Pablo jlopezm@ceu.es 
Tener incorporada la capacidad de perdonar y ponerla en marcha para manejar el malestar fruto de una ofensa, es fuente de bienestar psicológico y físico. Ese malestar puede ser mitigado de otras maneras, por ejemplo haciendo reatribuciones de las circunstancias que rodean la ofensa, aceptando el daño sin más, buscando restitución o exigiendo una disculpa, entre otras. No obstante, el perdón ha demostrado ser un recurso notable que merece una comprensión pormenorizada. Son numerosos los beneficios psicológicos que puede llegar a generar el perdón: disminución de la depresión, ansiedad y el estrés, mayor satisfacción vital y afecto positivo: optimismo, gratitud, esperanza; relaciones sociales positivas y mayor calidad de vida, incluso felicidad. El perdón es un regalo que uno se hace a sí mismo, ya que permite dejar atrás el resentimiento, la amargura y la rabia consecuencia de la ofensa, y también es un regalo que se ofrece al otro, porque posibilita su redención. El perdón reconoce la necesidad de que se haga justicia pero claramente va más allá. Por estas razones, es interesante centrarse en cómo educar en la capacidad de perdonar y de pedir perdón desde los primeros años de vida.

\section{Qué es perdonar}

El perdón es un fenómeno complejo que se produce cuando se da un cambio en distintos procesos psicológicos, especialmente en la motivación y en la emoción. Respecto al proceso motivacional, es habitual que tras sentirnos dañados, aparezca una motivación que busca evitar a la persona que ha dañado, y otra que pretende devolver el daño, es decir, vengarse. Según esto, habremos Ilegado a perdonar cuando descienden los deseos de evitación y venganza, y cuando aumenta la motivación por la benevolencia, es decir la compasión y el amor hacia quien dañó. De acuerdo con el proceso emocional, descrito como un "cambio de corazón", las emociones negativas fruto de la ofensa, como rabia, frustración, tristeza, acaban por desaparecer o incluso se transforman en positivas: empa-

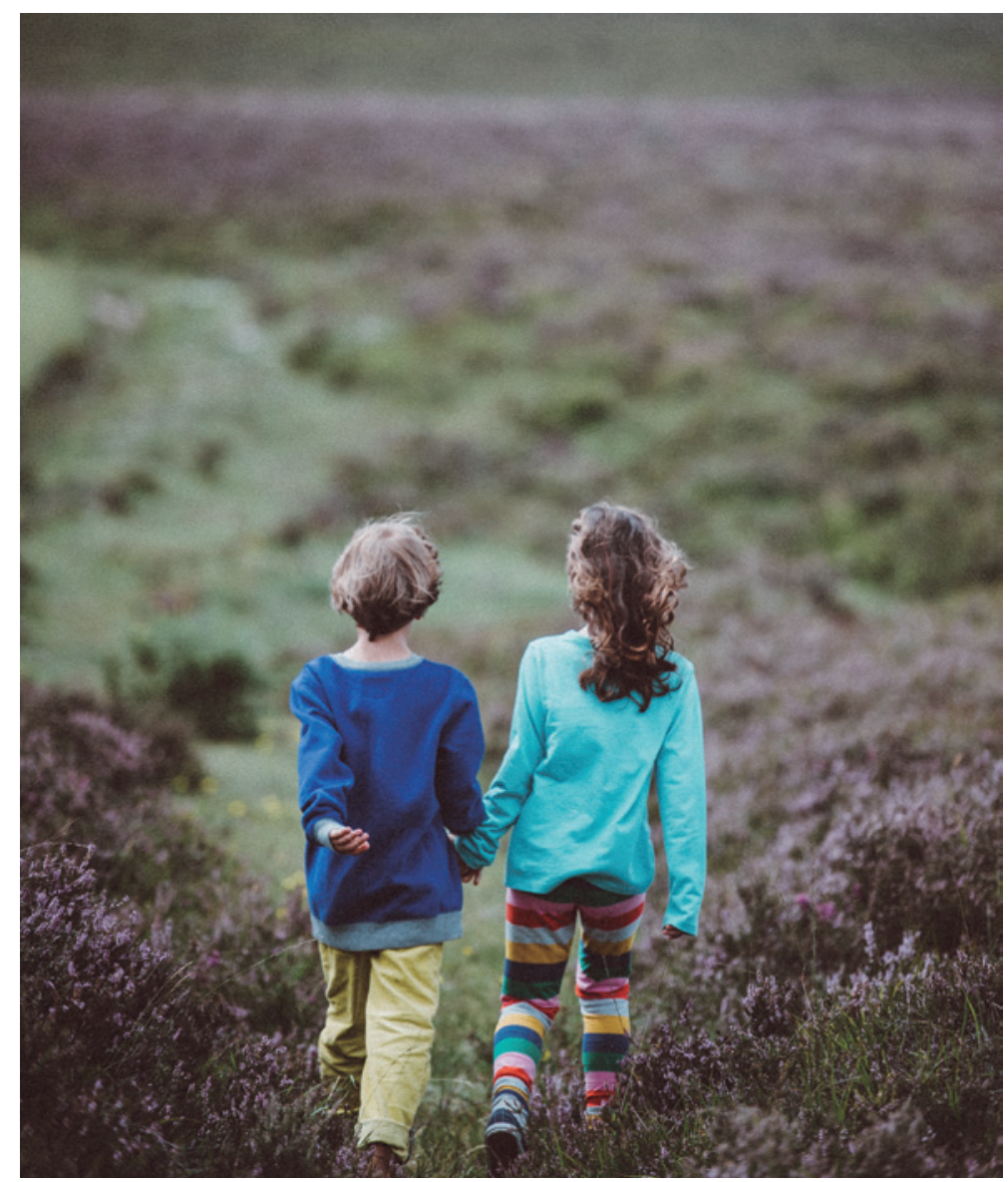

tía, simpatía, compasión e incluso amor. Además, se pueden dar también cambios en los pensamientos y en las conductas, siendo positivos y prosociales una vez se ha perdonado.

Perdonar es diferente que olvidar. Si se intenta olvidar una ofensa sin más, entonces ya no hay nada que perdonar. En efecto, no es posible borrar una ofensa que ha sido cometida, pero por el perdón sí es posible dejar atrás e incluso llegar a olvidar el resentimiento que brota de la ofensa. Para algunos padres y maestros es un reto explicar a los niños la combinación de "te perdono" con el "no lo vuelvas a hacer". De acuerdo con la diferencia establecida entre perdonar y olvidar, es posible enseñar a los niños que por el perdón los sentimientos y motivaciones han cambiado y ahora son positivos; cuando el niño escucha "te perdono", conviene que sepa que el daño que ha cometido tiene unas determinadas consecuencias, que es preferible tenerlas presentes para que no sean repetidas, ya que ha hecho daño a otra persona, le ha hecho sufrir, pasarlo mal y de ahí que "no lo vuelvas a hacer". 


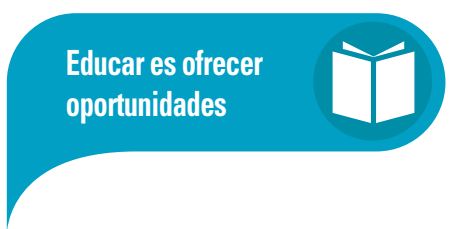

\section{El perdón es un regalo que uno se hace a sí mismo, ya que permite dejar atrás el resentimiento, la amargura y la rabia consecuencia de la ofensa, y también es un regalo que se ofrece al otro, porque posibilita su redención}

También existen diferencias destacables entre perdonar y reconciliarse. En general se considera que el perdón es un proceso interno, privado, un regalo que el ofendido le hace al ofensor, donde se dan los cambios ya mencionados, mientras que la reconciliación tiene que ver con restaurar la fractura en la relación. A pesar de ser conceptos diferentes, están estrechamente vinculados ya que perdonar es la principal causa de la reconciliación.

\section{Desarrollo de la capacidad de perdón}

¿Desde qué edad es posible perdonar? El desarrollo de la capacidad de perdonar, según Enright, se da en paralelo al desarrollo moral establecido por Kohlberg. La primera gran etapa del desarrollo moral, de la moral preconvencional, a partir de los 4 años y hasta los 9, incluiría los estadios 1 y 2 del desarrollo del perdón, por los que se plantea un perdón "vengativo" que se dará siempre que sea posible devolver un daño similar, y un perdón sujeto a "restitución y compensación", con el que el ofendido perdona porque ha vuelto a las condiciones previas a la ofensa y se siente culpable de no perdonar. La segunda etapa, de la moral convencional, parte de la adolescencia y en muchas personas se mantiene toda la vida. En esta etapa se incluyen los estadios 3 y 4 del perdón que consisten respectivamente en el perdón "sujeto a expectativas" y "sujeto a expectativas legalistas". El perdón "sujeto a expectativas" consiste en perdonar porque el entorno así espera que se haga. En el perdón "sujeto a expectativas legalistas" se perdona porque la religión u otras instancias así lo indican y los preceptos deben cumplirse. Finalmente, la tercera etapa, de la moral postconvencional, va más allá de las normas que rigen el funcionamiento en comunidad y apela a los grandes principios. Se incluyen aquí los estadios 5 y 6 , que hacen referencia al perdón "como armonía social" y al perdón "como amor". El perdón "como armonía social" busca el mantenimiento de la paz y las buenas relaciones en la sociedad, y el perdón "como amor" se refiere a un perdón desde la máxima incondicionalidad y solo porque ello promueve un verdadero sentido del amor y la misericordia; no todos los adultos alcanzan este estadio (las edades referidas en cada estadio son orientativas ya que realmente los estadios estarían en función del desarrollo cognitivo de cada niño).

Del planteamiento de Enright se deduce que habrá diferencias en la capacidad de perdonar entre niños de una misma clase y también entre hermanos con un desarroIlo cognitivo diferente, por lo que no tendrá sentido establecer comparaciones (por ejemplo "mira cómo tu hermana perdona y parece mentira que tu no"), sino más bien observar en qué punto se encuentra cada uno para poder comprender sus posibilidades en el momento actual, e incluir las explicaciones oportunas que ayuden a la comprensión del hecho sucedido.

Además, el planteamiento de Enright nos ayuda, como adultos, a identificar desde qué estadio de perdón funcionamos. Los estadios 1 y 2 se centran en el malestar de uno mismo y la necesidad de eliminarlo. Los estadios 3 y 4 buscan salvaguardar la buena imagen, ya sea ante uno mismo o ante los demás, mientras que los estadios 5 y 6 consideran central a los otros como sociedad, o al otro como fin último de sentido.

¿Qué ventajas puede tener que los niños aprendan a perdonar, o bien pidan perdón sinceramente? En primer lugar, aprender a responsabilizarse de las consecuencias de su comportamiento, en el caso de que ellos hayan obrado mal, y aprender a hacer respetar sus límites en el caso de que alguien los transgre- 
da con ellos. En segundo lugar, el perdón será de gran ayuda como herramienta de autorregulación para gestionar emociones, ya que por el perdón es posible que el resentimiento y la rabia se transformen en compasión. En tercer lugar, el perdón representa una habilidad esencial para sobrellevar con éxito las decepciones y conflictos que tienen lugar en las relaciones sociales, tanto con sus iguales como con los adultos.

\section{Cómo se perdona: proceso}

Existen distintos programas para facilitar el perdón. De manera general, los puntos en los que coinciden todos son los siguientes:

$\boldsymbol{\lambda}$ Reconocer que ha tenido lugar una ofensa y reconocer su importancia, tratando de ver la herida con perspectiva y equilibrio: sin tratarse como víctima y sin reaccionar exageradamente contra el ofensor. Se recomienda analizar las defensas (negación de la rabia, represión, desplazamiento) y los niveles de dolor: la rabia, la vergüenza, considerar la energía emocional agotada en reaccionar, tanta rumiación cognitiva recordando los detalles de lo que pasó, el duelo cuando el efecto de la ofensa produce un cambio permanente, y el malestar porque se ha podido romper el concepto de "mundo justo" que se tenía.

$\boldsymbol{\lambda}$ Considerar el punto de vista del ofensor, ya que un perdón sin entendimiento estaría incompleto. Esto permitirá captar las limitaciones de quien ha hecho daño, entender su parte vulnerable, sin restarle responsabilidad.

入 Empatizar con quien hizo el daño. Resulta de ayuda cuando además hay muestras de arrepentimiento y disculpas. Conviene dedicar el tiempo necesario ya que será la llave del cambio emocional y motivacional. Ayuda recordar las ocasiones en que uno mismo ha sido perdonado.

入 Decidir perdonar, expresar la decisión y comprometerse con ella. Profundizar tratando de dar sentido al sufrimiento

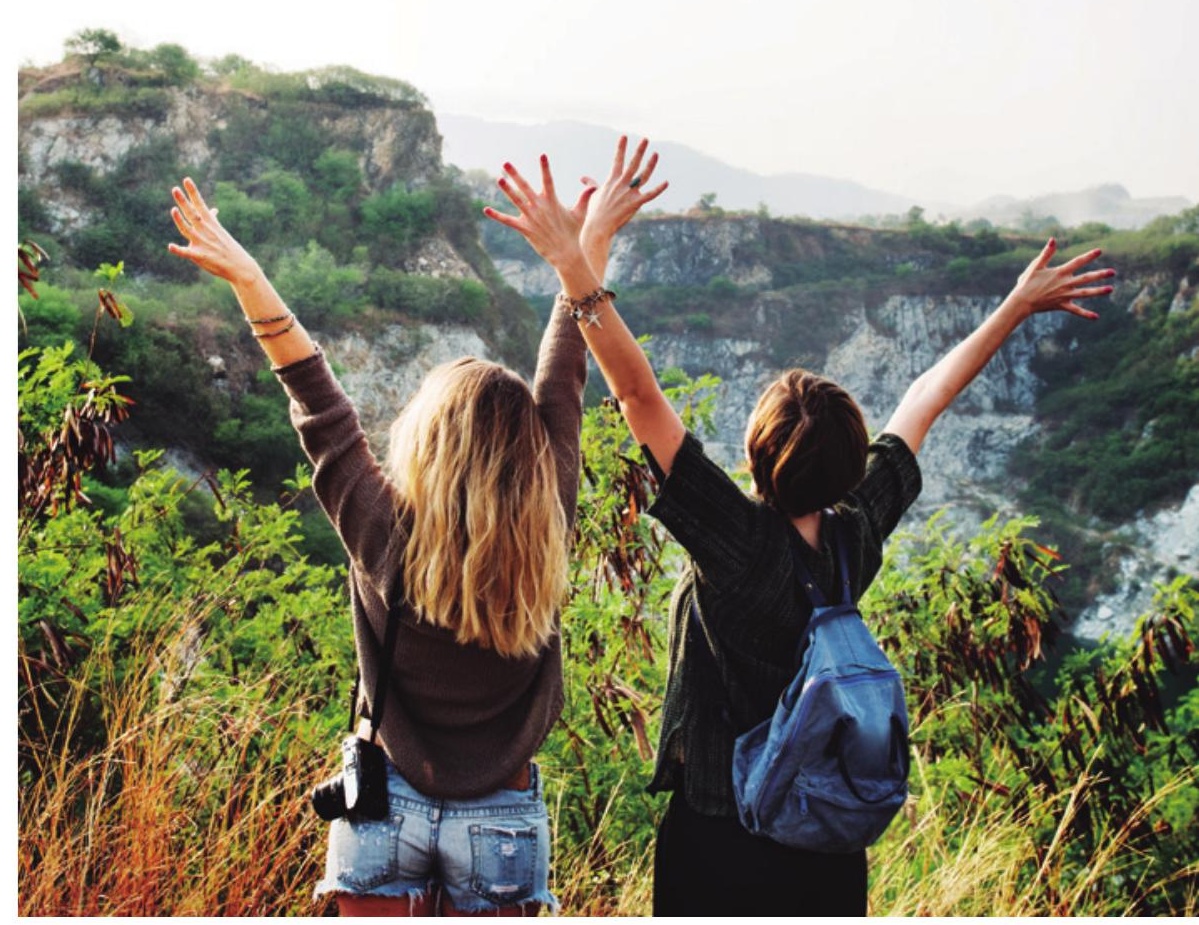

y al proceso de perdón, y caer en la cuenta de que uno cuenta con el apoyo de los demás. A veces puede surgir un nuevo propósito vital de compartir lo aprendido en el proceso.

El perdón es central en la religión católica y a menudo está asociado a un concepto de perdón incondicional, lo que puede facilitar el proceso, frente a conceptualizaciones condicionales en las que para perdonar es necesaria la presencia de disculpas y un arrepentimiento claro.

\section{El perdón en la familia}

En el ámbito familiar es inevitable sentirse en ocasiones herido u ofendido. Cuando la familia es capaz de cumplir con sus funciones básicas, puede lidiar con estos sentimientos de malestar y evitar la ruptura.

Es más frecuente el perdón por parte de los padres hacia los hijos, ya que es sencillo para ellos comprender su papel educador. Cuando un niño se siente perdonado puede distinguir que él es diferente de sus acciones, por lo que cuando se trata de una acción inadecuada o que 

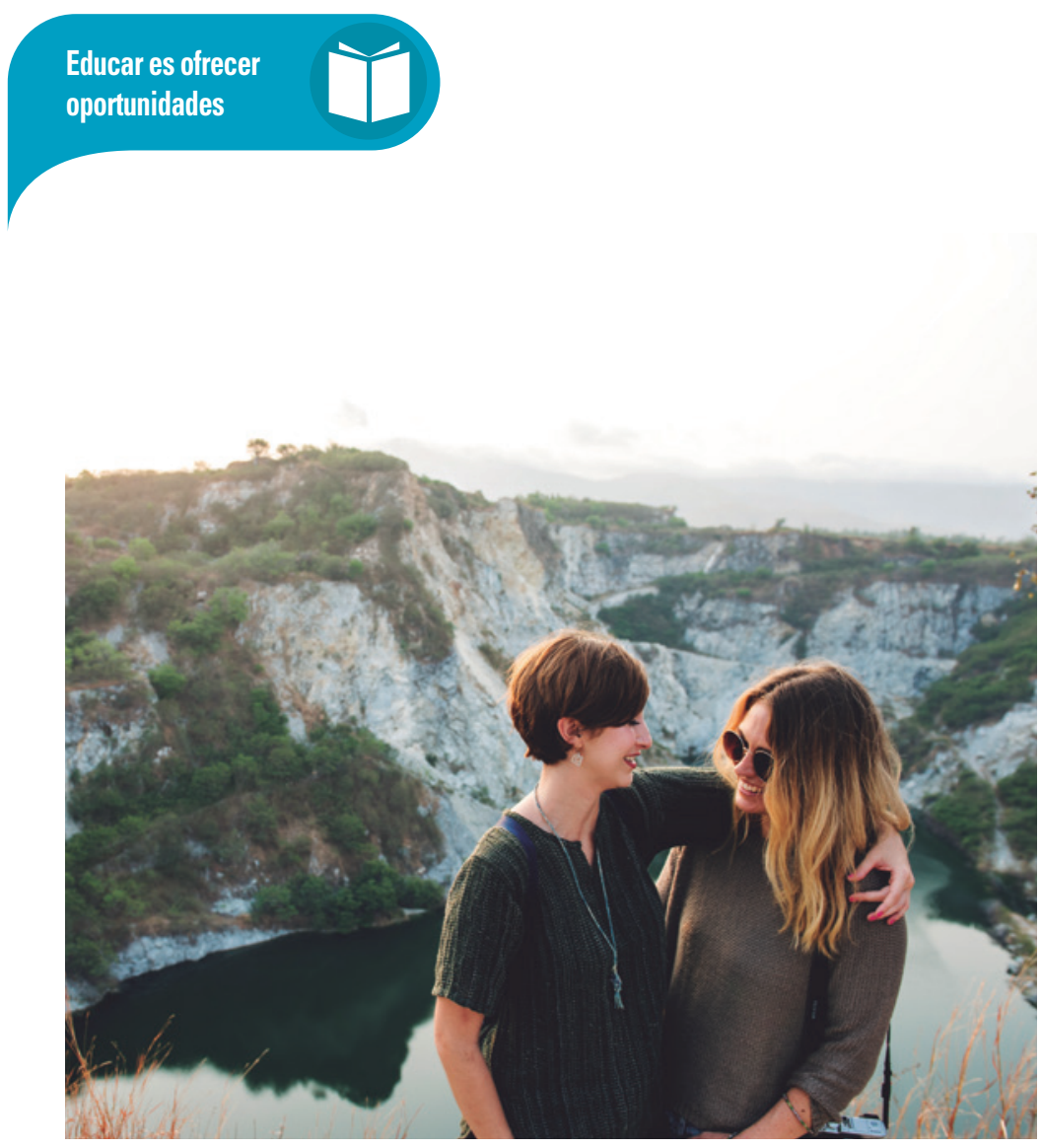

deseable compartir con los hijos que a veces hay diferencias en las relaciones, que uno tiene ganas y deseo de perdonar pero que aún no ha podido completarlo, aunque está en el proceso. Cuando se ha enseñado con eficacia que perdonar es un proceso, es fácil que los niños puedan comprender que, pese a que el perdón aún no se ha alcanzado, su padre o madre está en el camino de llegar a ello. Además conviene que la familia trasmita al niño que decir "te perdono" no es suficiente, sino que esas palabras se tienen que convertir en un cambio de actitud hacia la persona a la que se perdona.

De manera general, las familias en las que se da la expresión de perdón están más cohesionadas, tienen menos conflic-

daña, la construcción de su identidad queda preservada. Sabe que "he hecho algo mal" pero su vivencia no es la de "soy malo". El perdón adulto ayuda a que el niño reconozca el daño cometido, no se identifique con ese daño, comprenda las consecuencias negativas que ha provocado y se responsabilice de ellas. Darle al niño la posibilidad de restitución del daño permite que aprenda que hay una vía para solucionar las equivocaciones, y así será cada vez más capaz de pedir perdón, de perdonar y de promover el perdón.

Construir y cuidar el vínculo afectivo con los hijos es fundamental para desarrollar la base que permita que, aunque sucedan diferencias y desencuentros, que inevitablemente ocurren, se mantenga la confianza y el deseo de recuperar la relación. Gracias a esos lazos, esa comunicación, ese intercambio, esa expresión de afecto, esa historia compartida de buenos momentos, la familia se va configurando como lugar seguro donde, aunque puede haber problemas, no hay miedo a que se destruya y por lo tanto los conflictos no tengan la última palabra.

La familia es una escuela para aprender a perdonar. A veces los padres se preocupan porque les resulta difícil perdonar una ofensa. Su experiencia subjetiva es algo así como: "transmito a los niños que hay que perdonar siempre, pero yo no lo hago", y por ello se sienten cínicos. Es

\section{El perdón en las aulas}

La poca evidencia que hay sobre educar en el perdón en el contexto escolar plantea la conveniencia de crear espacios para hablar sobre diferentes aspectos relacionados con el perdón y sus implicaciones.

Como se ha mencionado anteriormente, el perdón reconoce la necesidad de que se haga justicia (justicia distributiva) pero va más allá de esta (justicia restaurativa). En el ámbito escolar, esto se torna real cuando hablamos del problema del bullying, que es el campo de aplicación más trabajado dentro del contexto escolar.

¿Cómo y cuándo puede la víctima de bullying utilizar el perdón en su beneficio? Sin duda perdonar al abusador puede ser la etapa final de un proceso de recuperación exitoso, que complemente a otras intervenciones que ayuden a la víctima a disminuir el enfado y la rumiación. Siempre deberá darse una etapa inicial de distanciamiento del abusador, para poder desarrollar más tarde hacia él la empatía que requerirá el proceso de perdón. El perdón se asocia a un ajuste socioemocional positivo en la adolescencia, aumentando la sensación de fuerza personal y de capacidad interpersonal, por permitir que la víctima ejerza control en ámbitos donde generalmente no lo ha hecho. Este senti- 
do de control incrementa la autoeficacia y facilita el acceso a mecanismos de afrontamiento más efectivos para manejarse en futuras situaciones. Todo ello repercute en menor ansiedad y mayor capacidad de resolución de conflictos y de búsqueda de apoyo. El perdón genera también empatía hacia el abusador, por lo que la víctima deja de hacer autoatribuciones de culpa, y disminuye la probabilidad de que reproduzca la agresión hacia sí misma, lo cual no haría sino aumentar la victimización.

Sin embargo, el perdón debe tomarse con precaución cuando se plantea en situaciones de maltrato. La expresión "el lado oscuro" del perdón subraya que una rapidez excesiva por parte de la víctima, o ponerlo demasiado fácil, podrían llevar al maltratador que no ha recorrido su proceso (reconocer el daño, responsabilizarse de ello, asumir las consecuencias, pedir perdón sincero, restituir en la medida de lo posible el daño causado), a mantener su dominio y a promover el mantenimiento del daño.

Además, no todas las formas de entender el perdón tienen como consecuencia efectos saludables. Para algunos el perdón es un regalo incondicional que puede hacer el sujeto por sí mismo, sin necesidad de que intervenga el ofensor; sin embargo, otros creen que el perdón depende de ciertas condiciones (que el ofensor reconozca lo sucedido, que pida perdón...). Pues bien, parece que el perdón condicional está asociado a mayores niveles de victimización en adolescentes entre 12 y 14 años.

\section{PARA SABER MÂS}

EnRight, R. (2017). Las 8 claves del perdón. Barcelona: Elefthería.

Prieto Ursúa, M. (2017). Perdón y Salud: Introducción a la psicología del perdón. Madrid: Universidad Pontificia Comillas.

Worthington, E. L. (2014). Forgiveness and reconciliation: Theory and Application. New York: Routledge.

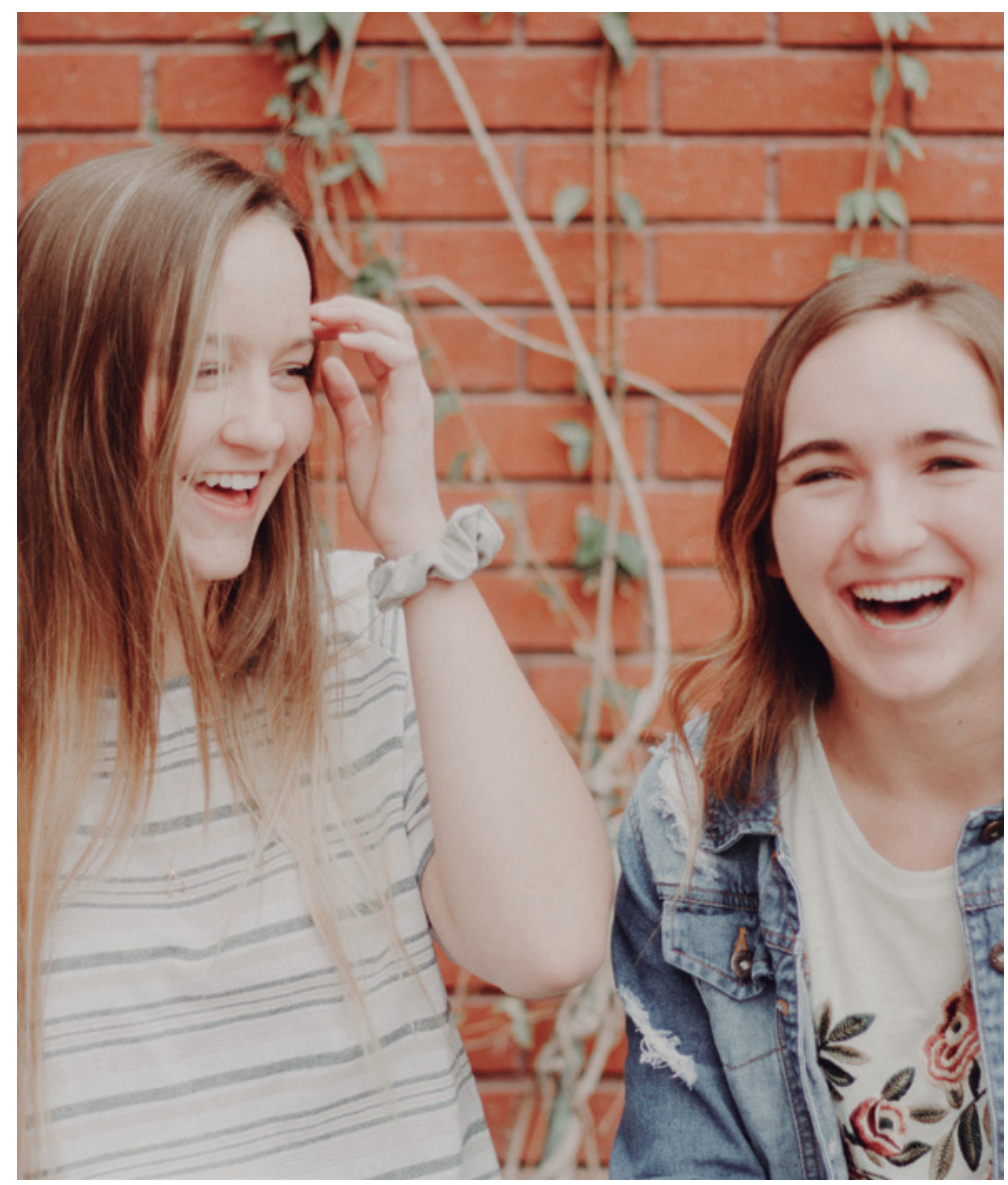

Podemos concluir afirmando que el perdón es un proceso complejo, requiere de tiempo y constituye un regalo para uno mismo y para los demás. La capacidad de perdonar está ligada al desarrollo cognitivo. El proceso de perdonar sigue unos pasos que están definidos. La fe puede ser un facilitador para perdonar. Aporta beneficios, tanto en la vida familiar como escolar. Perdonar no está exento de riesgos, es importante valorarlos, especialmente en situaciones de maltrato. Aprender cómo y cuándo perdonar es posible y permite una justicia que sitúa en la persona el fin último de sentido •

\section{HEMOS HABLADO DE}

\section{Bienestar; salud mental; educación; psicología; perdón.}

Este artículo fue solicitado por PADRES Y MAESTROS en diciembre de 2017, revisado y aceptado en marzo de 2018. 